\title{
Developing A-Freemium Mobile Games Software Based On Augmented Reality-Commerce
}

\author{
Ari Kusumaningsih ${ }^{1}$, Cucun Very Angkoso ${ }^{2}$, Ubaidillah $^{3}$ \\ Informatics Engineering Department \\ University of Trunojoyo Madura \\ Bangkalan, Indonesia \\ 1ari.kusumaningsih@trunojoyo.ac.id
}

\begin{abstract}
Marketing methods for selling software have experienced many changes. In-app Purchase Method (IAP) is one of the breakthrough solutions in selling a freemium software, where users can download and use the application for free, but there are premium features that must be paid. One of the challenges on the IAP system in mobile games is when choosing the type of payment media to buy a premium feature: several interruptions on internet connection and different server error may also reduce user satisfaction. This study aims to provide a solution by applying an Augmented Reality (AR) technology to the IAP system, so the system no longer requires an internet connection to the game server and the users easier to make the expenditure. The system is applied on the purchasing system in the Heroes of Surabaya mobile games which run on android operating system. Through AR technology, the purchasing system done by recognizing the markers. Thus, we contribute to provide an alternative solution for premium-app purchasing system, which normally it must be paid using digital money that not everyone recognizes and has it. So, the only need to do for every user who wants to buy premium feature/items in our mobile games is buying a marker card. From the experimental results, our application gets $96 \%$ user satisfaction from attractive sales innovations, but the speed only gets $35 \%$ of the level of user satisfaction. Light and distance markers are a key factor in the success rate in marker detection.
\end{abstract}

Keywords- Augmented Reality, In-App Purchase, Freemium, Mobile Game

\section{INTRODUCTION}

In-App purchase (IAP) system is believed to be more effective in attracting consumers than the existing payments method. When an application developer utilizes the method in the sale of an application, there is a possibility that the developer will earn more and more frequently from one user. Unlike paid applications where application developers usually get one-time revenue from one user for each application, they have sold. Along with the rapid development of mobile application technology, a variety of applications emerged in various ways to market them. Likewise, in mobile game applications. Mobile game application developers use a variety of ways to monetize their applications, such as In-App Advertising, Freemium, Paid Apps, IAP, Paywalls, and Sponsorship [1]-[3]. Several studies of user purchase behavior trends indicate that users prefer IAP and Freemium compared to payments in the beginning [4]-[7].

Our research aim to investigate an application of AR technology to an IAP system to improve user experience and provide alternative payment media solutions of the IAP system. Based on several studies shows that AR has a better market share compared to virtual reality. AR-app for commercial fields which called aCommerce is the second most popular in AR-app [8]-[10]. We are inspired by aCommerce from IKEA which utilizes AR technology in their sales catalog. The application is displaying the pictures of furniture to be purchased. Furthermore, users can immediately order the desired furniture by automatically connected to the IKEA webcommerce system, so that customers do not need to open the IKEA website or even visit the IKEA outlet to see the furniture model and place an order manually. [3].

We made the implementation of AR for IAP system based on paper-markers. It is for purchasing premium items and will be more suitable for being applied in mobile games as an innovative and attractive method. Furthermore, we have organized this article into a section for material, method, experiment result, analysis, and conclusion.

\section{A. Mobile Games}

Mobile games are video games that are built on mobile devices such as smartphones and tablet computers. While game consoles such as PlayStation or Nintendo are not considered mobile games. In its development, the emergence of smartphones and the availability of cellular internet changed the state of mobile games. The existence of a touch screen, high-quality graphics display, and the availability of connections to the network, offers a new experience for users. Moreover, users can download many applications and game variations from online application stores [2].

\section{B. In-App Purchase}

In-App Purchase (IAP) refers to a selling digital products from a mobile application, in the form of goods and services to users of the app [2]. This is another way to get profitability from software that can be sold at a low price or even free. IAP first introduced by Apple on the iOS platform. Currently, IAP is very popular among application developers, because they 
can develop their applications with the freemium model, where users can download their free apps, but users are provided with

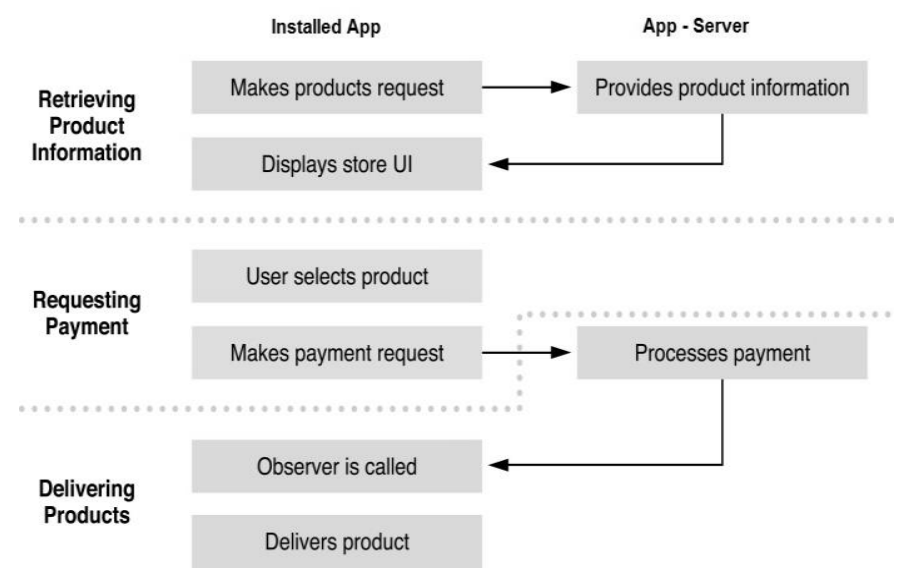

Fig. 1. Default InApp purchase system [4]

Premium features and content that can be purchased by users [4]. In the IAP system there are two payment models, i.e. standard (once paid) and subscription (pay for a certain period) [3]. Fig 1, shows the IAP system that already used in existing software-App. App with IAP usually very much need a stable internet connection to ensure transactions are not interrupted. The types of In-App Purchases products that we design refer to the recommendations proposed by APPLE as shown in Table 1 [5].

TABLE I. IN-APP PURCHASE PRODUCTS DESIGN [5]

\begin{tabular}{|l|l|l|}
\hline $\begin{array}{c}\text { Type of In- } \\
\text { App Purchase }\end{array}$ & \multicolumn{1}{|c|}{ Content } & \multicolumn{1}{c|}{ Description } \\
\hline Consumables & $\begin{array}{l}\text { Hp Extra } \\
\text { Experience Extra } \\
\text { Coin extra }\end{array}$ & $\begin{array}{l}\text { Consumables are disposable } \\
\text { items that require players to } \\
\text { buy when they need it. }\end{array}$ \\
\hline $\begin{array}{l}\text { Nonconsumabl } \\
\text { es }\end{array}$ & $\begin{array}{l}\text { Level -Up } \\
\text { Extra-Challenge }\end{array}$ & $\begin{array}{l}\text { Nonconsumables are items that } \\
\text { only need to be purchased } \\
\text { once, and can be used many } \\
\text { times. }\end{array}$ \\
\hline
\end{tabular}

\section{Augmented Reality (AR)}

$\mathrm{AR}$ is a technology that allows the immersion of virtual world into the real world. This technology has interactive and real-time properties. Through the identification of markers, 3D objects will appear in the real world [11]. Augmented Reality as a system that has the following characteristics:

- Combine real and virtual environments.

- Interactive ability with virtual objects in real time.

- Blending of three-dimensional objects into the real world.

Unlike Virtual Reality which makes the real world of users completely replaced by the virtual world, Augmented Reality is simply adding or completing a real environment by adding virtual objects in it. We used Vuforia AR software development kit (SDK) which available in https://developer.vuforia.com/downloads/sdk. Vuforia uses Computer Vision technology to recognize and track the markers (images target) and simple 3D objects at the real-time. There are several benefits by using the VUFORIA SDK, i.e. fast target detection, and robust system even in low light.

\section{MATERIAL AND METHOD}

This section discusses the concept material developed by the application that has been designed and the details of the methods used in designing the application. We have successfully created "Heroes of Surabaya" (HOS) mobile games. This mobile game takes the theme of the war events on Jembatan Merah 10 November 1945 in the City of Surabaya.

It is necessary to have a research methodology that contains the steps needed to build the application. Fig. 2 is our research methodology flowchart when building aCommerce on the mobile game HOS.

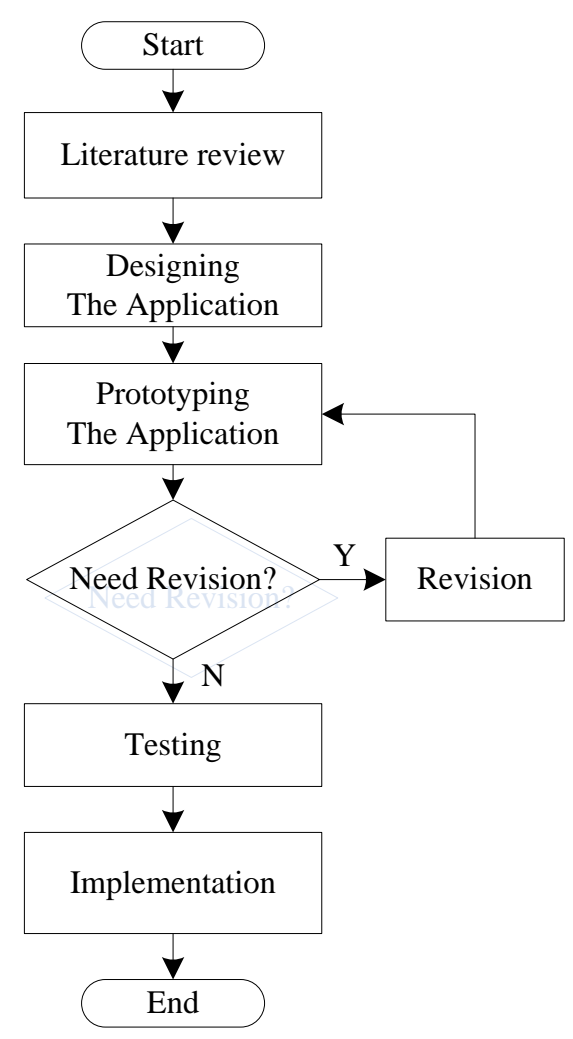

Fig. 2. Research flowchart

Fig. 3 describes the design flow of purchasing items in the shop menu. Purchases can be made by using coins; player will get the coin as a bonus when playing a game. Another payment method is using the AR method which requires the players to buy a marker card with real money.

When a player chooses to purchase an item using the coinbased method as the payment method, the coin player is subtracted according to the item price. All data is updated to the database of weapons and items; it will then display in real time. However, if the player chooses to purchase items by using AR as payment, the player will be directed to the ARshop menu. Fig. 4. show the ARshop menu flowchart. 


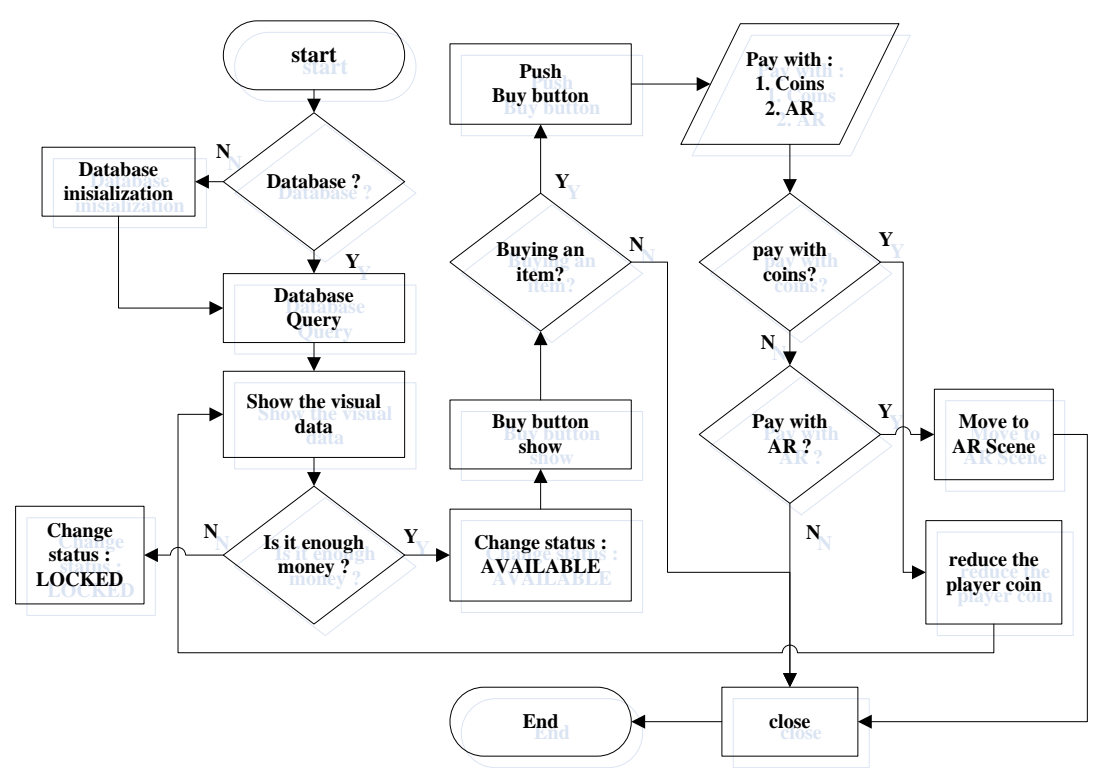

Fig. 3. The proposed system in AR purchasing system

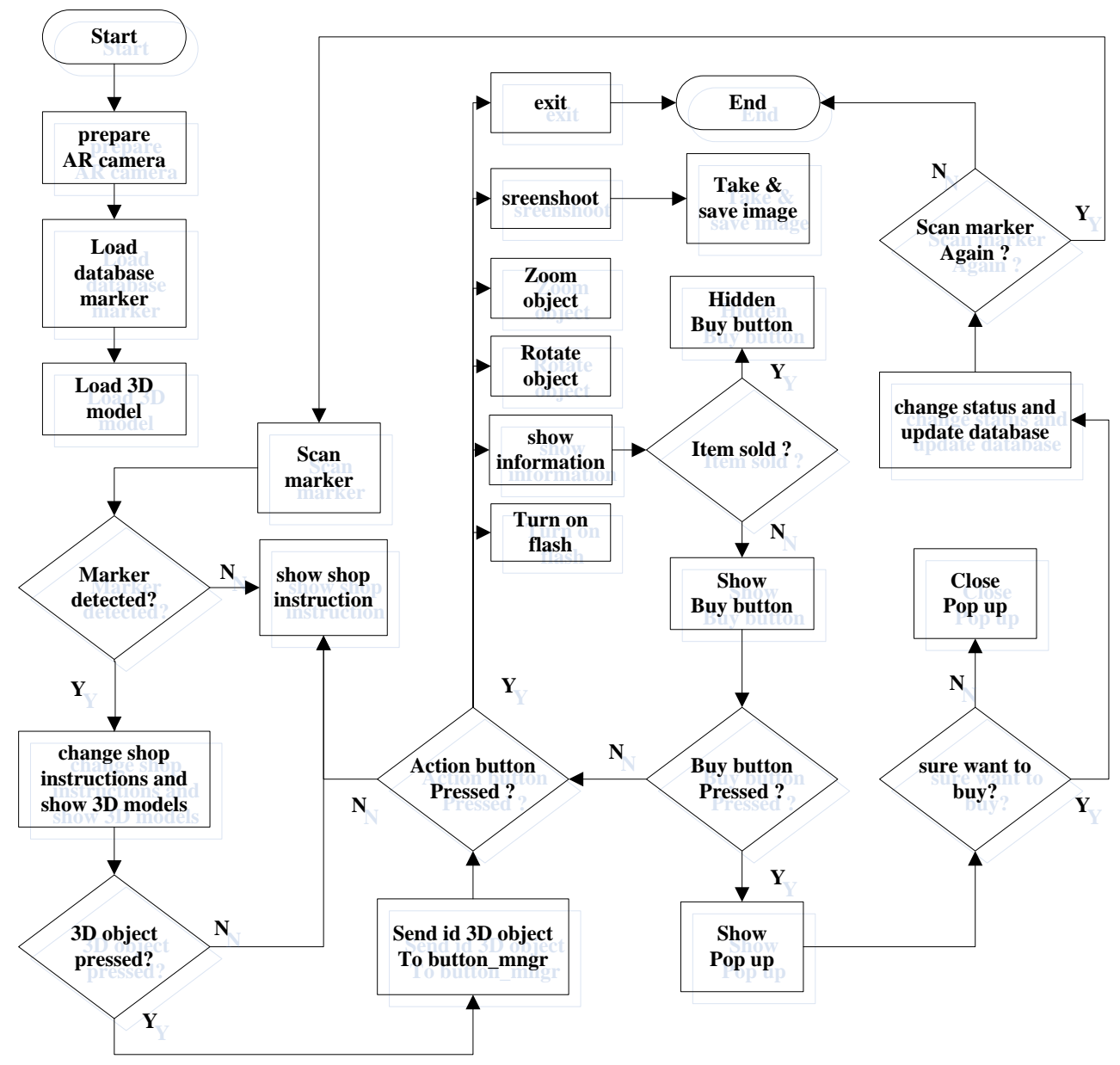

Fig. 4. ARshop menu flowchart 
ARshop will then handle user transactions when the payment option is using AR-markers. Players will be able to interact and purchase the items according to markers which associated with specific 3D objects.

The Marker which used in our Augmented Reality Shop is a full-color marker (not only in black and white, but designed as a card which may later be a player collection. Design of the marker images are matched, regarded to the 3D objects that will be displayed so that players do not need to memorize the contents of each marker when they want to purchase items. Markers are also explained the content in it so that it can be more informative and useful. The sample of the marker is shown in Fig 5.

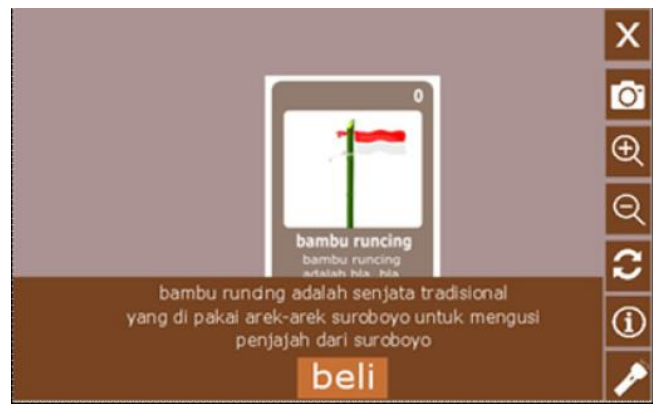

Fig. 5. A sample of markers design

\section{EXPERIMENT RESULT AND ANALYSIS}

\section{A. IAP AR Implementation}

The application of the IAP system using AR was carried out in the Heroes of Surabaya game, which tells the story of the struggle for Indonesia's independence in Surabaya. This 2dimensional (2D) Real Time Strategy (RTS) game provides a variety of weapon items that can be purchased using a coin or AR marker cards.

When a player chooses to do purchase items using the coin as payment media, the coin player is reduced according to the price of the item purchased and all data later updated to the weapon database and items for then displayed live in real-time. But if the player chooses to buy items using AR as payment, then the player will be directed to the scene ARshop.

ARshop will handle transactions using marker as a medium for generating 3D objects. Players can interact and do purchase items according to the marker. ARshop able to provide solutions for payment media at in the IAP system by using marker as the payment medium. Examples of AR marker target images in a match the weapons and items in the game, appear in Fig. 6.

The marker is uploaded to the VUFORIA Developer website https://developer.VUFORIA.com/targetmanager and entered in one database. The file has been uploaded and then assessed for quality by the system from Fuvoria as in Fig. 7.

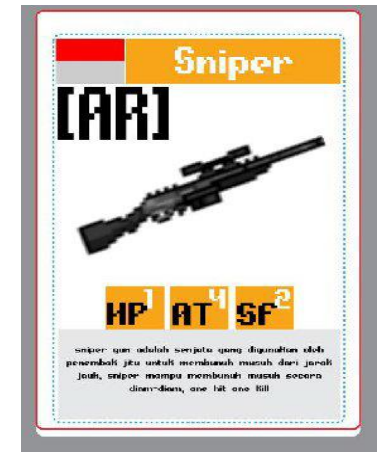

Fig. 6. Weapon Marker.

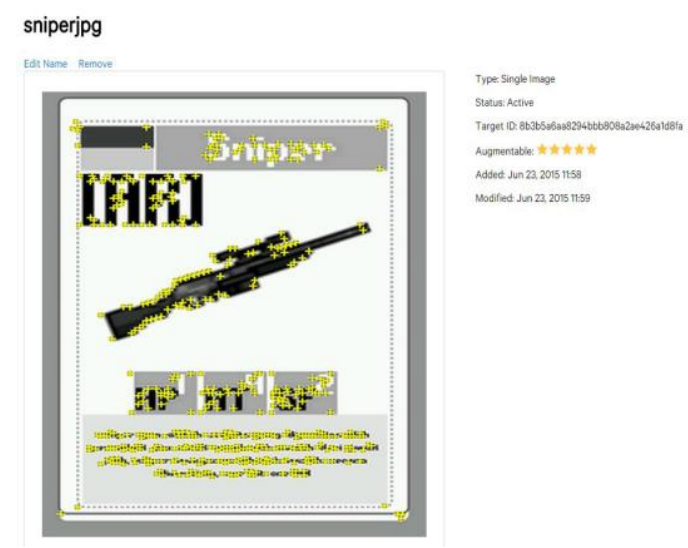

Fig. 7. Marker Rating

Fig. 7. shows that the uploaded marker was got five stars from Vuforia. The more stars, the better the detection process. The marker has been uploaded and then downloaded in format .unitypackage so that it can be read and exported to UNITY software. The uploader must be downloaded back to be included in the AR project. Markers can be downloaded on the same site when uploading it, and select UNITY editor as an option on the select platform.

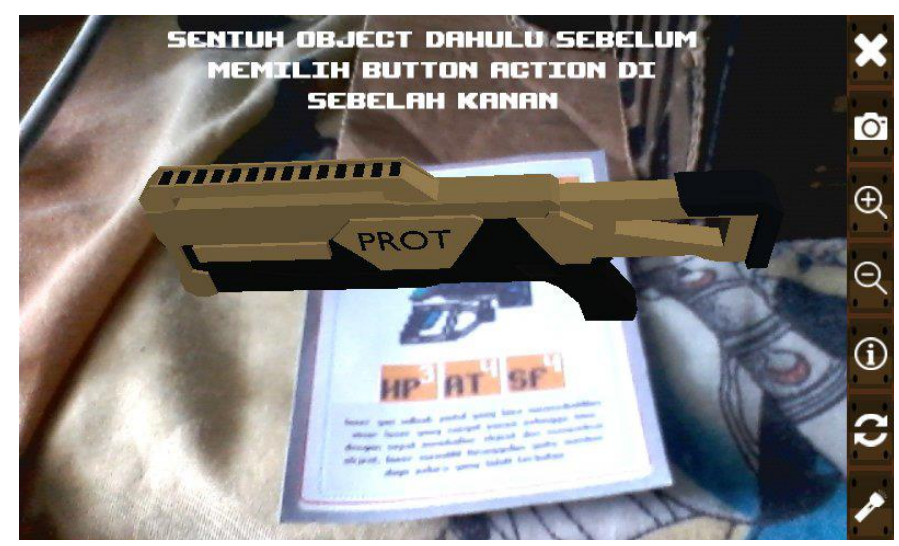

Fig. 8. AR shop interface

Fig. 8. show the ARShop display which designed to make user easier to choose the command they want. The button only 
located on the right, lined vertically. The button next to the top right corner is the exit button which used to exit ARShop goes back to the shop page. Screenshot button is used to capture the screen that the user wants. The zoom in button is useful for enlarging 3D objects desired, and the zoom out button to shrink $3 \mathrm{D}$ object. Below, it is the information button which containing information item, and also bring up the buy button if previously the item has not been purchased, so the user can directly buy the item inside this page. The rotation button used to rotate objects, so players can see various blades of 3D objects they want to buy. And the lower right corner button is the button flashlight which is useful for turning on flashlights to help marker capture when the marker scan is done in dim light conditions.

\section{B. Hardware implementation}

We do hardware implementation test to ensure the system and all the features are running as we planned. The prototype of the software is tested using different devices with different specifications. Three different smartphones are used in this stage. The purpose of this step is to find errors in the application. The test results can be seen in Table II. The results of the tests that have been carried out concluded that the game "Heroes of Surabaya" with aCommerce features runs well in various testing devices. All the functional analysis of the application features are showing that all the features of the application run well in all devices.

TABLE II. TRIAL ON VARIOUS DEVICES

\begin{tabular}{|l|l|l|}
\hline \multicolumn{1}{|c|}{ Device } & \multicolumn{1}{|c|}{ Specification } & Result \\
\hline $\begin{array}{l}\text { Andromax } \\
\text { C }\end{array}$ & $\begin{array}{l}\text { OS. V4.1. } \\
\text { CPU Dual-Core 1 GHz. } \\
\text { RAM 512MB. } \\
\text { 2 MP. }\end{array}$ & Good \\
\hline $\begin{array}{l}\text { Sony } \\
\text { Xperia E3 } \\
\text { Dual }\end{array}$ & $\begin{array}{l}\text { OS. V4.4.2. } \\
\text { CPU Quad-Core 1.2 GHz. }\end{array}$ & \\
& $\begin{array}{l}\text { RAM 1 GB. } \\
\text { 5 MP + Flash }\end{array}$ & \\
\hline Galaxy E5 & OS. V.4.4.4 & Good \\
& CPU Quad-Core 1.2 GHz. & \\
& $\begin{array}{l}\text { RAM 1.5 GB } \\
5 \mathrm{MP}+\text { Flash }\end{array}$ & \\
\hline
\end{tabular}

\section{User Experience Measurement}

Testing the application functionality at this alpha stage is done using questionnaires involving 30 respondents. Testing utilizing this questionnaire gives ten questions, which are classified based on application functionality, user experience testing, and testing based on application benefits.

TABLE III. USER RESPONS MEASUREMENT

\begin{tabular}{|c|c|c|c|c|c|c|c|c|c|}
\hline \multicolumn{10}{|c|}{ Category } \\
\hline \multicolumn{10}{|c|}{ Questionnaire Result (\%) } \\
\hline $\mathbf{1}$ & $\mathbf{2}$ & $\mathbf{3}$ & $\mathbf{4}$ & $\mathbf{5}$ & $\mathbf{6}$ & $\mathbf{7}$ & $\mathbf{8}$ & $\mathbf{9}$ & $\mathbf{1 0}$ \\
\hline 35 & 64 & 82 & 78 & 96 & 76 & 51 & 85 & 77 & 74 \\
\hline
\end{tabular}

Table III shows the test results are based on the application functionality, the speed of running the application gets the lowest value of the level of user satisfaction according to the application functionality category which is $35 \%$, and the ability of the application to run according to its function get the value the highest is $82 \%$. Whereas regarding user experience, the design of markers was ranked lowest of the level user satisfaction according to the user experience category that is equal to $51 \%$, and Augmented Reality that attracts users to purchase items in the game get the highest score of $96 \%$. On the side of the benefits of the application, the willingness of the user to use the app gets the lowest value from the level of user satisfaction according to the utility benefit category which is $74 \%$, while providing application benefits to users as payment innovations from the In-app purchase system gets the highest score of $77 \%$.

\section{CONCLUSION AND FURTHER RESEARCH}

The novelty in this study is the creation of the Heroes of Surabaya mobile game which tells the history of the Surabaya people's struggle for independence and the implementation of AR technology to the IAP system. This study contribute to provide an alternative solution for premium-app purchasing system, which normally it must be paid using digital money.

From the results of the survey of the majority of users interested in AR commerce as alternative payments in IAP with a satisfaction level of $96 \%$, but users feel the application is too slow to get a level satisfaction of $35 \%$ of users. This study succeeded in applying the AR trade as an IAP purchase, but there was a need to improve the quality of the game Heroes of Surabaya, to improve the perception purchased.

The advantage of this application is the ease of purchasing an item, no need for an internet connection, only requires AR markers. The drawback is the low speed of the purchase process, due to the influence of light received by AR markers. For further research, it is necessary to study on security procedures and accuracy of the use of AR markers, in order to prevent fraud in the purchasing process.

\section{ACKNOWLEDGMENT}

We thank internal reviewer of Engineering Faculty, University of Trunojoyo Madura for assistances and comments to make this manuscript greatly improved.

\section{REFERENCES}

[1] R. Sifa, F. Hadiji, J. Runge, A. Drachen, K. Kersting, and C. Bauckhage, "Predicting Purchase Decisions in Mobile Free-to-Play Games," Proceedings, The Eleventh AAAI Conference on Artificial Intelligence and Interactive Digital Entertainment (AIIDE-15), pp. 79-85, 2015.

[2] K. L. Hsiao and C. C. Chen, "What drives in-app purchase intention for mobile games? An examination of perceived values and loyalty," Electronic Commerce Research and Applications, vol. 16, pp. 18-29, 2016.

[3] Y. K. Oh and J. Min, "The mediating role of popularity rank on the relationship between advertising and in-app purchase sales in mobile application market," Journal of Applied Business Research, vol. 31, no. 4, pp. 1311-1322, 2015.

[4] P. Roma and D. Ragaglia, "Revenue models, in-app purchase, and the app performance: Evidence from Apple's App Store and Google Play," 
Electronic Commerce Research and Applications, vol. 17, pp. 173-190, 2016.

[5] S. W. Shi, M. Xia, and Y. Huang, "From Minnows to Whales: An Empirical Study of Purchase Behavior in Freemium Social Games," International Journal of Electronic Commerce, vol. 20, no. 2, pp. 177207, 2015.

[6] K. K. Kimppa, O. I. Heimo, and J. T. Harviainen, "First dose is always freemium," ACM SIGCAS Computers and Society, vol. 45, no. 3, pp. 132-137, 2016.

[7] J. Hamari, N. Hanner, and J. Koivisto, "Service quality explains why people use freemium services but not if they go premium: An empirical study in free-to-play games," International Journal of Information Management, vol. 37, no. 1, pp. 1449-1459, 2017.
[8] B. H. Thomas, "A survey of visual, mixed, and augmented reality gaming," Computers in Entertainment, vol. 10, no. 3, pp. 1-33, 2012.

[9] T. Olsson, E. Lagerstam, T. Kärkkäinen, and K. Väänänen-VainioMattila, "Expected user experience of mobile augmented reality services: A user study in the context of shopping centres," Personal and Ubiquitous Computing, vol. 17, no. 2, pp. 287-304, 2013.

[10] P. A. Rauschnabel, A. Rossmann, and M. C. tom Dieck, "An adoption framework for mobile augmented reality games: The case of Pokémon Go,” Computers in Human Behavior, vol. 76, pp. 276-286, 2017.

[11] R. Van Krevelen, "A Survey of Augmented Reality Technologies , Applications and Limitations A Survey of Augmented Reality Technologies , Applications and Limitations," The International Journal of Virtual Reality, vol. 9, no. 2, pp. 1-20, 2010. 